\title{
Radically Embodied Compassion: The Potential Role of Traditional Martial Arts in Compassion Cultivation
}

\author{
Neil Clapton ${ }^{1 *}$ and Syd Hiskey ${ }^{2}$ \\ ${ }^{1}$ Avon and Wiltshire Mental Health Partnership NHS Trust, Swindon, United Kingdom, ${ }^{2}$ Private Practice, The Oaks Hospital, \\ Colchester, United Kingdom
}

Keywords: martial arts, compassion, radically embodied, polyvagal theory, conflict resolution

\section{INTRODUCTION}

The last few years have seen a growing interest and research into the science of compassion, including exploring how we can best cultivate this important and powerful affiliative/prosocial motivation and its behavioral manifestations in humans (Gilbert, 2019). This has resulted in a proliferation of various compassion cultivation programmes and interventions (Kirby, 2017; Kirby

OPEN ACCESS

Edited by:

James Kirby,

The University of

Queensland, Australia

Reviewed by:

Yasmina Jraissati,

Ronin Institute, United States

${ }^{*}$ Correspondence:

Neil Clapton

claptonneil@gmail.com

Specialty section: This article was submitted to Theoretical and Philosophical

Psychology,

a section of the journal

Frontiers in Psychology

Received: 24 April 2020

Accepted: 21 August 2020 Published: 25 September 2020

Citation:

Clapton N and Hiskey S (2020)

Radically Embodied Compassion: The

Potential Role of Traditional Martial

Arts in Compassion Cultivation.

Front. Psychol. 11:555156. doi: 10.3389/fpsyg.2020.555156 et al., 2017), both for clinical and non-clinical populations. Many of these programmes contain both similarities and differences in regards to the specific mind training practices they draw on to stimulate the proposed neurophysiological processes associated with compassionate motivation and behaviors (Gilbert, 2019; Kim et al., 2020).

Whilst Western science has begun to consider ways of more fully embodying compassion (Loizzo, 2018; Khoury, 2019), it has thus far failed to consider the potentially powerful role of ancient cultural practices such as the traditional martial arts in cultivating compassion. This is despite the fact that the purpose and philosophy of many traditional martial arts is to develop certain virtuous character strengths (Hackney, 2011) in order to become a fearlessly courageously compassionate human being (Kamen, 2017). This opinion paper shall briefly outline the rationale for and extol the potential benefits of the traditional martial arts in entraining compassion at a radically embodied level (Hiskey and Clapton, 2019a), including related research that already supports this theoretical proposition.

\section{MARTIAL ARTS AS RADICALLY EMBODIED COMPASSION The Nature of Compassion and Its Neurophysiological Correlates and Indicators}

Whilst debates remain about the nature of and how to define compassion (Gilbert, 2017; Khoury, 2019), there is growing consensus that compassion is most usefully defined as "a sensitivity to suffering in self and others, with a commitment to try to alleviate and prevent it" (Gilbert and Choden, 2013, p. 94). A commonality among evolutionary, motivational and Buddhist psychology is to see compassion as a motive, likely rooted in evolved caring and affiliative motivational systems (Gilbert, 2015, 2017, 2019). From this perspective, at the core of compassion is courage and wisdom, in terms of (1) courageous willingness and emotional strength to turn toward, empathically engage with and tolerate distress; and (2) dedication to learn and develop skills/skillful means to take wise action in alleviating and preventing/halting suffering. 
At a neurophysiological level, Polyvagal Theory (Porges, 2007, 2011) proposes that compassion is associated with and dependent on a vagally-mediated physiological state and activation of the parasympathetic nervous system (Porges, 2017; Stellar and Keltner, 2017) that is functionally distinct from empathy and affords feelings of personal safety, as a result of simultaneously encompassing the feeling of one's own bodily responses while acknowledging those of the other (Porges, 2017).

Key to compassion then is that it allows one to stay engaged with suffering without becoming overwhelmed or overly distressed by it (Wilson and Takuan, 2012), reducing fear whilst affording and sustaining compassionate responding in difficult and challenging situations (Ashar et al., 2019).

\section{Radically Embodied Compassion as Understood, Cultivated and Entrained by the Traditional Martial Arts}

Compassion is a central tenet, ethical intention and motivational force integral to the "Way" of many traditional martial arts, including aikido (Westbrook and Ratti, 1970), taekwondo (Cook, 2006) and karate (Kamen, 2017). Traditional martial arts philosophy and systems are commensurate with the aforementioned conceptualization of compassion, as a motive to empathically confront and take wise skillful action to reduce and prevent suffering of self and others (Ueshiba, 2007). At their core, traditional martial arts are mind-body selfcultivation systems (Sovereign and Walker, 2020) that help develop compassionate and virtuous character strengths such as courage, benevolence, wisdom, temperance and justice (Hackney, $2011,2013)$. Seen from this perspective, martial arts can become a vehicle and pathway to reducing suffering, promoting well-being and flourishing at a personal and social level (Hackney, 2013; Sovereign and Walker, 2020).

The neuroscience of embodiment proposes and elucidates the centrality of the body in influencing and shaping motivational, emotional and cognitive processes (Price et al., 2012). Experimental evidence has demonstrated how intentionally-manipulated bodily states, such as dynamic/static body posture and quality/shape of movement, influence physiological responses associated with approach and avoidance motivations, emotional processing and perception (Price et al., 2012; Osypiuk et al., 2018). Such theory and research helps to provide an explanatory framework as to how and why traditional martial arts may be a form of Radically Embodied Compassion. Our proposition is that traditional martial arts training involves harnessing and training the whole self via a multitude of integrated mind-body practices that stimulate/give rise to compassionate motivation and associated mental states, emotions and behaviors, in the service of halting or reducing suffering.

Existing research already supports the notion that traditional martial arts afford, entrain and stimulate (neurophysiological) processes that are associated with and underpin compassionate motivation and compassionate responding (Kim et al., 2020). Such training aims to develop ease of access to a psychophysiological state characterized by courageous, swift, and precise responsiveness in the face of threats (Faggianelli and Lukoff, 2006). Thus, one can respond skillfully and flexibly from a position of inner centeredness, relative calm and stability (Martin, 2004; Wilson and Takuan, 2012), a state of mind that is reflective of and affords wise courageous compassionate engagement and action (Ueshiba, 2007). For example, rather than flinching or turning away in the face of physical confrontation, one might enact entrained procedures to block and counter it with one's own skillful actions. Recent fMRI research into the effects of mind-body training through Budo in Kendo practitioners on the motivation network supports this notion, in that "resting vs. attentionally-driven" switching/change of motivation can be trained and becomes more efficient (Fujiwara et al., 2019), which is indicative of an unmoving/undisturbed/unfettered mind (Wilson and Takuan, 2012) which better affords an appropriate physical response. Research also suggests that martial artists are more endogenously prepared to engage with and respond to uncertainty (Johnstone and Marí-Beffa, 2018) and are more distress tolerant when faced with and despite repeated exposure to threatening situations (Staller et al., 2017), as well-having greater sustained attentional abilities and impulse control (Sánchez-López et al., 2013; Sánchez-Lopez et al., 2016). All of this combines to lead to skillful action that is reasoned, assertive and conflict-ending rather than mindlessly aggressive and designed to excessively hurt another.

The power of martial arts as a mind-body practice and discipline potentially lies in their ability to foster optimal sympathovagal balance that affords flexible and optimal compassionate responding. Similar other mind-body practices such as Tai Chi, Qigong and yoga that pair mindful movement with breathing/breath control exercises have been shown to stimulate the parasympathetic nervous system (Ramos et al., 2017; Sullivan et al., 2018; Walther et al., 2018) and many martial forms/kata have sections that are deliberately practiced in a slow, controlled and meditative way (Rawcliffe, 2003). Paced rhythmic breathing synchronized with rhythmic muscle contraction activates and produces a more resilient parasympathetic response in the face of stress than either alone (Chin and Kales, 2019), both of which are integral to martial arts practice and are often seen in prearranged practice drills (i.e., Kihon), all conducted with respect for oneself and one's partner.

Research into behavioral synchrony is directly relevant to the processes which are stimulated by martial arts training. Group activities where people engage in synchronized movements, expressive gestures and collective rituals such as those found in martial arts training have been shown to enhance compassion for others via processes of shared flow and perceived emotional synchrony (Pizarro et al., 2020). Such collective behavioral synchrony has been proposed to help cultivate and enhance compassion because it likely co-stimulates affiliative and co-operative social mentalities (Friedman, 2016; Gilbert, 2017) that facilitates reciprocal empathic and altruistic responding (Valdesolo and DeSteno, 2011; Pizarro et al., 2020) even when enacting confrontation related (i.e., fight) behavior. 
All martial arts involve some form of carefully managed and safe combat (i.e., sparring or Kumite), whereby two or more practitioners are engaged in a dynamic process of antagonistic engagement, skillful responding and co-regulation (Kimmel and Rogler, 2019) that ends in reaffiliation and mutual respect at the end of the encounter/confrontation (e.g., bowing or touching gloves). Importantly, these are dyadic prosocial encounters (Rassovsky et al., 2019) that require moving from asynchronous to synchronous interactions and states. Such encounters require martial artists to rapidly and flexibly shift between socio-motivational states, otherwise referred to as Locomotion Motivation (Webb et al., 2017), an ability which is crucial in facilitating conflict resolution, post-conflict reconciliation, learning and growth (Webb et al., 2017). Martial arts might be implicitly and explicitly entraining value-driven abilities to stay affiliatively engaged in conflict situations of high relational threat and end such conflicts by reaffiliating, with minimum harm done. Thus, martial artists develop the courage and confidence to face and resolve conflicts nonviolently and compassionately, whereby potential suffering is halted and prevented and relational harmony is restored. This is compassionate conflict resolution and transformation (Martin, 2004; Friedman, 2016; Lukoff and Strozzi-Heckler, 2017; Hiskey and Clapton, 2019a).

Sparring also often involves some form of physical touch and contact either via blocking and/or grappling. Such martial arts training has been shown to increase endogenous oxytocin production (Rassovsky et al., 2019), a neuropeptide that plays a central role in regulating mammalian social behaviors by down-regulating threat-based processing and defensive behaviors and up-regulating affiliative and prosocial behaviors associated with compassion. Taken together, traditional martial arts training and practices maybe a particularly powerful way of neurally exercising vagal circuits and pathways of what has been termed the Social Engagement System (Porges, 2017).

Crucially, such compassion and compassionate abilities cultivated and entrained by the martial arts are likely transferable to non-martial situations, through a process which has been termed somatic metamorphism (Foster, 2015). This has been described as a mode of deploying the body to make sense of and wisely respond to nonmartial challenges such as day-to-day relational conflicts and challenges, supported by first-person accounts of Aikido practitioners' somatic metamorphism in everyday life (Foster, 2015). In this way, martial values of care for ourselves and others generalize from the dojo/training hall to one's broader relational context(s).

\section{Clinical and Non-clinical Applications of Martial Arts-Based Compassion Cultivation}

The potential utility of martial arts as a vehicle for cultivating compassion is broad and multifarious. In terms of clinical applications, there is emerging theory that entraining radically embodied compassion in therapists/clinicians via traditional martial arts may afford them greater distress tolerance and compassionate responsiveness in difficult therapeutic encounters such as alliance ruptures (Faggianelli and Lukoff, 2006; Hiskey and Clapton, 2019a,b), where repair of and reaffiliation after such ruptures are central to good therapeutic outcomes (Safran et al., 2002; Eubanks-Carter et al., 2015). Martial artsaugmented personal practice thus has the potential to help develop specific compassionate competencies that not only benefit others but also the self (Twemlow, 2001a,b; Hiskey and Clapton, 2019a,b) by enhancing the flow of compassion (Gilbert et al., 2017), as well as acting as an important form of compassionate self-care for mental health professionals (Gladstone, 2018).

Traditional martial arts training and practices also hold promise as a compassion-focused psychotherapeutic intervention in their own right and/or as an adjunct to other psychotherapies. Early evidence suggests that martial arts training is a potentially powerfully transformative intervention for individuals who have experienced interpersonal trauma (Vargas, 2019), possibly because of martial arts' highly embodied and somatic-based nature that is akin to other somaticallyinformed psychotherapies that target the amelioration and healing of trauma more directly via the body (Ogden and Fisher, 2015; Van der Kolk, 2015; Loizzo, 2018). Martial arts-informed psychotherapy may also be a more compassionate way to reach and help alleviate the suffering of individuals whom find it extremely difficult to access and benefit from verbal therapies alone, such as people whose traumatic histories and upbringings lead to acting out destructive aggression and a relative inability to mentalize about others or the self (Twemlow et al., 2008).

In terms of cultivating and engendering compassion at a social level, traditional martial arts has much to offer. It has the potential to decrease and prevent the suffering engendered by inevitable interpersonal conflicts that occur in day-to-day life, and promote more prosocial behaviors associated with compassionate motives by embodying and enacting non-violent conflict resolution and facilitated post-conflict reaffiliation (Martin, 2004; Foster, 2015; Friedman, 2016; Lukoff and StrozziHeckler, 2017; Hiskey and Clapton, 2019a). A growing body of research and evidence supports the notion that longerterm training in traditional martial arts reduces aggressiveness and increases prosocial behaviors (Blomqvist Mickelsson, 2019). Some of these other compassionate behaviors include the development and expression of prosocial assertiveness and helpful bystanding (Twemlow et al., 2008) as well as respect for others, perseverance, self-confidence, and healthy habits (Chinkov and Holt, 2015).

\section{CONCLUSION}

This paper has outlined how the traditional martial arts may be powerful ways of cultivating radically embodied compassion. Western science has thus far largely ignored and neglected the ancient wisdom of the traditional martial arts as vehicles for compassion cultivation and training. Our hope is that this paper will stimulate further research into the underlying mechanisms of martial arts practices and their relationship to 
compassion, as well as the further development of martial artsbased psychotherapies and personal practices that help cultivate compassion for all.

\section{REFERENCES}

Ashar, Y. K., Andrews-Hanna, J., Halifax, J., Dimidjian, S., and Wager, T. (2019). Effects of compassion training on brain responses to suffering others. bioRxiv [Preprint]. doi: 10.1101/616029

Blomqvist Mickelsson, T. (2019). Modern unexplored martial arts-what can mixed martial arts and Brazilian Jiu-Jitsu do for youth development? Eur. J. Sport Sci. 20, 386-393. doi: 10.1080/17461391.2019.1629180

Chin, M. S., and Kales, S. N. (2019). Understanding mind-body disciplines: a pilot study of paced breathing and dynamic muscle contraction on autonomic nervous system reactivity. Stress Health 35, 542-548. doi: 10.1002/smi.2887

Chinkov, A. E., and Holt, N. L. (2015). Implicit transfer of life skills through participation in Brazilian Jiu-Jitsu. J. Appl. Sport Psychol. 28, 139-153. doi: 10.1080/10413200.2015.1086447

Cook, D. (2006). Traditional Taekwondo: Core Techniques, History, and Philosophy. Boston, MA: YMAA Publication Center.

Eubanks-Carter, C., Muran, J. C., and Safran, J. D. (2015). Alliance-focused training. Psychotherapy 52:169. doi: 10.1037/a0037596

Faggianelli, P., and Lukoff, D. (2006). Aikido and psychotherapy: a study of psychotherapists who are Aikido practitioners. J Transperson Psychol. $38,159-178$

Foster, D. (2015). Fighters who don't fight: The case of aikido and somatic metaphorism. Qual. Sociol. 38, 165-183. doi: 10.1007/s11133-015-9305-4

Friedman, H. L. (2016). Using Aikido and transpersonal psychology concepts as tools for reconciling conflict: focus on Aikido and related martial arts, such as Hapkido. NeuroQuantology 14, 213-225. doi: 10.14704/nq.2016.14.2.938

Fujiwara, H., Ueno, T., Yoshimura, S., Kobayashi, K., Miyagi, T., Oishi, N., et al. (2019). Martial arts "Kendo" and the motivation network during attention processing: an fMRI study. Front. Human Neurosci. 13:170. doi: 10.3389 /fnhum. 2019.00170

Gilbert, P. (2015). The evolution and social dynamics of compassion. Soc. Personal. Psychol. Compass 9, 239-254. doi: 10.1111/spc3.12176

Gilbert, P. (Ed.). (2017). Compassion: Concepts, Research and Applications. London: Routledge.

Gilbert, P. (2019). Explorations into the nature and function of compassion. Curr. Opin. Psychol. 28, 108-114. doi: 10.1016/j.copsyc.2018.12.002

Gilbert, P., Catarino, F., Duarte, C., Matos, M., Kolts, R., Stubbs, J., et al. (2017). The development of compassionate engagement and action scales for self and others. J. Compassion. Health Care 4:4. doi: 10.1186/s40639-017-0033-3

Gilbert, P., and Choden. (2013). Mindful Compassion: Using the Power of Mindfulness and Compassion to Transform Our Lives. London: Constable \& Robinson.

Gladstone, J. (2018). Are Martial Arts an Effective Self-Care Practice for Mental Health Professionals? (Doctoral dissertation): Antioch University.

Hackney, C. (2011). Martial Virtues: Lessons in Wisdom, Courage, and Compassion From the World's Greatest Warriors. North Clarendon, VT: Tuttle Publishing.

Hackney, C. H. (2013). "Martial arts as a pathway to flourishing," in Positive psychology: Advances in Understanding Adult Motivation, ed J.D. Sinnott (New York, NY: Springer), 145-158.

Hiskey, S., and Clapton, N. (2019a). The martial arts and embodied distress tolerance in psychological therapy. Int J Martial Arts 5:4

Hiskey, S., and Clapton, N. (2019b). Rolling with the punches: the martial arts as a vehicle for personal and therapist self-development. Private Pract. 6-9.

Johnstone, A., and Marí-Beffa, P. (2018). The effects of martial arts training on attentional networks in typical adults. Front. Psychol. 9:80. doi: 10.3389/fpsyg.2018.00080

Kamen, R. K. (2017). Karate: Beneath The Surface: Emotional Content of Kata. Newyork, NY: Kamen Entertainment Group.

Khoury, B. (2019). Compassion: embodied and embedded. Mindfulness 10, 2363-2374. doi: 10.1007/s12671-019-01211-w

\section{AUTHOR CONTRIBUTIONS}

NC and SH contributed to this topic and writing equally.

Kim, J. J., Cunnington, R., and Kirby, J. N. (2020). The neurophysiological basis of compassion: An fMRI meta-analysis of compassion and its related neural processes. Neurosci. Biobehav. Rev. 108, 112-123. doi: 10.1016/j.neubiorev.2019.10.023

Kimmel, M., and Rogler, C. R. (2019). The anatomy of antagonistic coregulation: emergent coordination, path dependency, and the interplay of biomechanic parameters in Aikido. Human Move. Sci. 63, 231-253. doi: 10.1016/j.humov.2018.08.008

Kirby, J. N. (2017). Compassion interventions: The programmes, the evidence, and implications for research and practice. Psychol. Psychotherap. 90, 432-455. doi: $10.1111 /$ papt.12104

Kirby, J. N., Tellegen, C. L., and Steindl, S. R. (2017). A meta-analysis of compassion-based interventions: current state of knowledge and future directions. Behav. Therap. 48, 778-792. doi: 10.1016/j.beth.2017.06.003

Loizzo, J. J. (2018). Can embodied contemplative practices accelerate resilience training and trauma recovery? Front. Human Neurosci. 12:134. doi: 10.3389/fnhum.2018.00134

Lukoff, D., and Strozzi-Heckler, R. (2017). Aikido: A martial art with mindfulness, somatic, relational, and spiritual benefits for veterans. Spiritual. Clin. Pract. 4, 81-91. doi: 10.1037/scp0000134

Martin, P. (2004). Conflict resolution using transactional analysis and aikido. Transact. Anal. J. 34, 229-242. doi: 10.1177/036215370403400307

Ogden, P., and Fisher, J. (2015). Sensorimotor Psychotherapy: Interventions for Trauma and Attachment (Norton Series on Interpersonal Neurobiology). New York, NY: WW Norton \& Company.

Osypiuk, K., Thompson, E., and Wayne, P. M. (2018). Can Tai Chi and Qigong postures shape our mood? Toward an embodied cognition framework for mind-body research. Front. Human Neurosci. 12:174. doi: 10.3389/fnhum.2018.00174

Pizarro, J. J., Basabe, N., Amutio, A., Telletxea, S., Harizmendi, M., and Van Gordon, W. (2020). The mediating role of shared flow and perceived emotional synchrony on compassion for others in a mindful-dancing program. Mindfulness 11, 125-139. doi: 10.1007/s12671-019-01200-z

Porges, S. W. (2007). The polyvagal perspective. Biol. Psychol. 74, 116-143. doi: 10.1016/j.biopsycho.2006.06.009

Porges, S. W. (2011). The Polyvagal Theory: Neurophysiological Foundations of Emotions, Attachment, Communication, and Self-Regulation (Norton Series on Interpersonal Neurobiology). New York, NY: WW Norton \& Company.

Porges, S. W. (2017). "Vagal pathways: portals to compassion," in The Oxford Handbook of Compassion Science, ed E.M. Seppala (New York: NY, Oxford University Press), 189-204.

Price, T. F., Peterson, C. K., and Harmon-Jones, E. (2012). The emotive neuroscience of embodiment. Motivat. Emotion 36, 27-37. doi: 10.1007/s11031-011-9258-1

Ramos, C. C., de França, E., Nobre, T. L., Santana, J. O., Madureira, D., Zocoler, C. A. S., et al. (2017). Qi Gong and heart rate variability: a systematic review. J. Biosci. Med. 5, 120-127. doi: 10.4236/jbm.2017.53013

Rassovsky, Y., Harwood, A., Zagoory-Sharon, O., and Feldman, R. (2019). Martial arts increase oxytocin production. Sci. Rep. 9:12890. doi: 10.1038/s41598-019-49620-0

Rawcliffe, S. (2003). Simply Wing Chun Kung Fu. Ramsbury: The Crowood Press Ltd.

Safran, J. D., Muran, J. C., Samstag, L. W., and Stevens, C. (2002). "Repairing alliance ruptures," in Psychotherapy Relationships That Work: Therapist Contributions and Responsiveness to Patients, ed J.C. Norcross (New York, NY: Oxford University Press), 235-254.

Sánchez-López, J., Fernández, T., Silva-Pereyra, J., and Mesa, J. A. M. (2013). Differences between judo, taekwondo and kung-fu athletes in sustained attention and impulse control. Psychology 4, 607-612. doi: $10.4236 /$ psych. 2013.47086 
Sánchez-Lopez, J., Silva-Pereyra, J., and Fernández, T. (2016). Sustained attention in skilled and novice martial arts athletes: a study of event-related potentials and current sources. PeerJ 4:e1614. doi: 10.7717/peerj.1614

Sovereign, G., and Walker, B. R. (2020). Mind, body and wellbeing: reinforcement sensitivity theory and self-cultivation systems as wellbeing influencers. $J$. Happiness Studies, 1-20. doi: 10.1007/s10902-019-00216-5

Staller, M. S., Zaiser, B., Körner, S., and Cole, J. C. (2017). Threat-related attentional biases in police officers and martial artists: investigating potential differences using the E-Stroop and dot probe task. Sage Open 7:2158244017712776. doi: $10.1177 / 2158244017712776$

Stellar, J. E., and Keltner, D. (2017). "Compassion in the autonomic nervous system: the role of the vagus nerve," in Compassion: Concepts, Research and Applications, ed P. Gilbert (London: Routledge), 120-134.

Sullivan, M. B., Erb, M., Schmalzl, L., Moonaz, S., Noggle Taylor, J., and Porges, S. W. (2018). Yoga therapy and polyvagal theory: the convergence of traditional wisdom and contemporary neuroscience for self-regulation and resilience. Front. Human Neurosci. 12:67. doi: 10.3389/fnhum.2018.00067

Twemlow, S. W. (2001a). Training psychotherapists in attributes of "mind" from Zen and psychoanalytic perspectives, part I: Core principles, emptiness, impermanence, and paradox. Am. J. Psychother. 55, 1-21. doi: 10.1176/appi.psychotherapy.2001.55.1.1

Twemlow, S. W. (2001b). Training psychotherapists in attributes of "mind" from Zen and psychoanalytic perspectives, part II: attention, here and now, nonattachment, and compassion. Am. J. Psychothe. 55, 22-39. doi: 10.1176/appi.psychotherapy.2001.55.1.22

Twemlow, S. W., Sacco, F. C., and Fonagy, P. (2008). Embodying the mind: Movement as a container for destructive aggression. Am. J. Psychother. 62, 1-33. doi: 10.1176/appi.psychotherapy.2008.62.1.1

Ueshiba, M. (2007). The Art of Peace (Translated and Edited by John Stevens). Boston: Shambhala.
Valdesolo, P., and DeSteno, D. (2011). Synchrony and the social tuning of compassion. Emotion 11, 262-266. doi: 10.1037/a0021302

Van der Kolk, B. A. (2015). The Body Keeps the Score: Brain, Mind, and Body in the Healing of Trauma. Penguin Books.

Vargas, A. G. (2019). Psychological Effects of Training in Martial Arts After Interpersonal Trauma. (Doctoral dissertation): Walden University.

Walther, A., Lacker, T. J., and Ehlert, U. (2018). Everybody was Kung-Fu fighting-The beneficial effects of Tai Chi Qigong and self-defense Kung$\mathrm{Fu}$ training on psychological and endocrine health in middle aged and older men. Complement. Therap. Med. 36, 68-72. doi: 10.1016/j.ctim.2017. 11.021

Webb, C. E., Coleman, P. T., Rossignac-Milon, M., Tomasulo, S. J., and Higgins, E. T. (2017). Moving on or digging deeper: Regulatory mode and interpersonal conflict resolution. J. Personal. Soc. Psychol. 112, 621-641. doi: $10.1037 /$ pspp0000131

Westbrook, A., and Ratti, O. (1970). Aikido and the Dynamic Sphere: An Illustrated Introduction. North Clarendon, VT: Tuttle Publishing.

Wilson, W. S., and Takuan, S. (2012). The Unfettered Mind: Writings From a Zen Master to a Master Swordsman. Boston: Shambhala Publications.

Conflict of Interest: The authors declare that the research was conducted in the absence of any commercial or financial relationships that could be construed as a potential conflict of interest.

Copyright (c) 2020 Clapton and Hiskey. This is an open-access article distributed under the terms of the Creative Commons Attribution License (CC BY). The use, distribution or reproduction in other forums is permitted, provided the original author(s) and the copyright owner(s) are credited and that the original publication in this journal is cited, in accordance with accepted academic practice. No use, distribution or reproduction is permitted which does not comply with these terms. 